\title{
IMITAÇÃO E FAZER PRECONCEITO: CIRCULAÇÃO DE OBJETOS, ROUPAS, MODAS E JEITOS ENTRE OS WAJÃPI (AMAPÁ) ${ }^{1}$
}

\author{
CAMILA GALAN DE PAULA ${ }^{2}$
}

UNIVASF

\begin{abstract}
RESUMO: Em aldeias wajãpi no Amapá, muitos rapazes e homens ostentam penteados à Neymar; mulheres jovens repartem os cabelos de lado; meninas pequenas trajam apenas calcinhas. Diversas práticas e ornatos que parecem à primeira vista ter seu uso oriundo nas cidades amapaenses remetem a relações de pessoas wajãpi com outros povos indígenas: os sutiãs inspirados nas mulheres wajãpi das aldeias do Camopi (Guiana Francesa), o lambadão xinguano. As imitações de práticas corporais e o uso de objetos cujas origens são atribuídas a outros grupos (indígenas e não indígenas) são profusos. Este artigo pretende explorar algumas considerações de meus interlocutores wajãpi a respeito de dinâmicas ligadas à aquisição $e$ circulação desses objetos, roupas, modas e enfeites. Inicialmente analiso a ideia de imitação, a partir de um diálogo entre meus dados e a bibliografia acerca dos corpos ameríndios. A partir dessa dinâmica da imitação, revelam-se também certas relações sociopolíticas entre diversas pessoas e famílias wajãpi: imita-se aquilo que alguém fez primeiro; esses iniciadores, por sua vez, buscam diferenciar-se, fazendo preconceito ou disputa.
\end{abstract}

PALAVRAS-CHAVE: corpo; vestimentas; roupas; ornamentação corporal; circulação de mercadorias; Wajãpi (Tupi-guarani).

ABSTRACT: In Wajãpi villages, several young men wear they hair inspired in (soccer player) Neymar's hairstyle. Young women part their hair sideways; female toddlers wear nothing but underpants. Many of these bodily practices and garments are related by the Wajapi to exchange networks established with other Amerindian peoples. The use of bras was inspired by Wajãpi women on the French Guiana villages of Camopi, the musical genre lambadão was taught by Xingu peoples. Abundant are bodily practices and objects which imitation is attributed by the Wajäpi to other groups (Amerindians and non-indigenous ones). The article aims to analyze the acquisition and circulation of objects and clothes among the Wajãpi. I explore the idea of to imitate (imitar), analyzing data produced through fieldwork in the light of literature on South Amerindian bodies. The imitation dynamic casts light on certain sociopolitical relations among

\footnotetext{
${ }^{1}$ A pesquisa que originou estas reflexões foi realizada no âmbito de um mestrado realizado no Programa de Pós-Graduação em Antropologia Social da Universidade de São Paulo e contou com uma bolsa da Fundação de Amparo à Pesquisa do Estado de São Paulo (FAPESP), processo 2012/23868-3. Tal pesquisa foi continuada no âmbito de um projeto de pesquisa cadastrado junto à Universidade Federal do Vale do São Francisco sob o título Estudos sobre roupas e povos ameríndios. O presente artigo reelabora discussões do segundo capítulo de minha dissertação e foi parcialmente apresentado no $40^{\circ}$ Encontro Anual da Anpocs, em outubro de 2016, no seminário temático Redes de relações indígenas.

${ }^{2}$ Professora-assistente no Colegiado de Antropologia da Universidade Federal do Vale do São Francisco (UNIVASF), Campus Serra da Capivara. Mestre em Antropologia Social pela Universidade de São Paulo. E-mail: camila.galan@univasf.edu.br.
} 
different Wajãpi families and individuals: one imitates what someone else did first. The person who initiates said actions, on their turn, seeks to be different from others, making prejudice (fazer preconceito) or competition (disputa).

KEYWORDS: body; garments; clothes; commodity circulation; Wajäpi (Tupi-guaranian).

\section{Introdução}

Este artigo originou-se da realização de um mestrado em antropologia social, e contou com pesquisa de campo entre os Wajãpi no Amapá, população falante de uma língua tupi-guarani, no período entre outubro de 2014 e março de 2015, quando realizei duas etapas de campo $^{3}$. Orientada pela leitura de trabalhos de antropólogos cujas reflexões analisam a circulação de mercadorias entre populações indígenas das terras baixas sul-americanas (entre os quais: DAL POZ, 2004; EWART, 2013 a e 2013b; GORDON, 2006; GROTTI, 2013; HUGHJONES, 1992; WALKER, 2012 e 2013), a investigação centrou-se na análise de dinâmicas de aquisição, circulação e consumo de objetos industrializados pelos Wajãpi ${ }^{4}$.

Sinteticamente, este artigo visa apresentar dois conjuntos de disposições entrelaçadas que, segundo os Wajãpi, movem a aquisição de objetos e modas. Dentre tais coisas, algumas delas vindas das cidades. Outras, por sua vez, originam-se alhures: em aldeias wajãpi na Guiana Francesa ou no Parque Indígena do Xingu, por exemplo. Trato, em primeiro lugar, da dinâmica da imitação. Em segundo lugar, da disputa.

\footnotetext{
${ }^{3}$ Tendo frequentado a Terra Indígena Wajãpi posteriormente, ao longo de 2015 e 2016, em atividades de indigenismo e extensão universitária, creio ser possível pensar que as dinâmicas aqui analisadas continuam a ocorrer, ainda que alguns exemplos etnográficos - sobretudo algumas modas de vestimentas e adornos - pudessem ser constantemente atualizados. Fui bolsista da Ação Saberes Indígenas na Escola, do Ministério da Educação, Núcleo USP-UFMG, e fui corresponsável por ministrar cursos de política para mulheres wajãpi em parceria com o Instituto de Pesquisa e Formação Indígena (Iepé), organização indigenista não governamental

${ }^{4}$ Refiro-me a bens industrializados, mercadorias, objetos ou produtos industrializados para designar as coisas adquiridas nas cidades. Ciente das distinções conceituais entre mercadoria, bem e dádiva (cf. GREGORY, 1982 e 1997), não me valho desses conceitos por entender, assim como Cesar Gordon (2006, p. 48-49), que tais discussões não iluminam minha etnografia. Compreender os critérios usados pelos Wajãpi para estabelecer distinções (ou não) entre coisas compradas nas cidades ou feitas em aldeias foi também objetivo da dissertação, e é algo tratado lateralmente neste artigo.
} 
Entendo que há dois sentidos principais para a lógica da imitação sobre os quais me falaram os Wajãpi. Inicialmente abordarei o modo como a imitação corresponde a pegar o jeito das pessoas imitadas. Também pode-se falar em imitação quando o espraiamento de determinada moda é atribuído à imitação que as pessoas fazem do iniciador de tal prática. Fazer disputa ou fazer preconceito articula-se à imitação: as práticas que são imitadas foram inicialmente realizadas por alguém - e essa pessoa, em alguns casos, pode ser reconhecida como alguém que faz disputa. Nessa dinâmica de circular jeitos, ornamentos, práticas corporais e saberes, imiscuem-se hoje o dinheiro e as possibilidades de obtê-lo, via salários ou benefícios sociais. Esse é um tema que aparecerá apenas tangencialmente na reflexão aqui proposta.

Previamente às discussões enunciadas, sigo com breves apresentações (i) das relações presentes e pretéritas dos Wajãpi com mercadorias e (ii) das vestimentas e ornamentos que esses índios usam nas aldeias.

\section{Os Wajãpi e as mercadorias}

Foi muito antes do contato oficial com a Funai em 1973 que as famílias wajãpi passaram a lidar com diferentes bens industrializados. Mapeando os deslocamentos que, a partir de cerca de 1700, levaram grupos falantes de uma língua tupi-guarani do baixo rio Xingu à região sudoeste das Guianas - então habitada por povos de língua caribe e aruak -, Dominique T. Gallois (1986) relata a participação dos ascendentes dos atuais Wajãpi nas redes de relações da região, em que circulavam inclusive mercadorias de origem europeia.

Houve três levas principais de migração wajãpi: a primeira fixouse no início do século XIX nas bacias do alto rio Araguari, e dos rios Oiapoque e Camopi. A segunda onda chegou em cerca de 1840 ao médio rio Jari e posteriormente deslocou-se para o rio Cuc. Essas duas levas iniciais deram origem aos grupos Wajãpi que atualmente vivem na Guiana Francesa. Os Wajãpi no Oiapoque francês entraram em conflitos com grupos Wayana, Emerillon e com o grupo afroamericano Boni entre 1790-1850. O contato com os franceses - mediado pelos índios Piriu 
- no início do século XIX rendia-lhes mercadorias. É provável que também tivessem contato mais esporádico com brasileiros. Já os Wajãpi que no início do século XIX viviam no alto Jari estabeleceram relações com balateiros, com o intuito de conseguir armas e ferramentas. Após conflitos com gateiros e balateiros, nos anos 1930, deslocaram-se para o rio Cuc e o contato com brancos passou a ser mais esporádico (GALLOIS, 1986).

A terceira leva migratória oriunda do baixo Xingu deu origem aos Wajãpi que vivem contemporaneamente no Brasil. Esses grupos ocuparam o médio rio Jari (1800-1840), o baixo rio Inipuku (18401860 ) e posteriormente se expandiram para afluentes dos rios Jari e Araguari, a partir de 1860 (GALLOIS, 1986, p. 132-3). Esses grupos wajãpi entraram em conflito com povos de língua caribe que viviam na região. O contato com brasileiros, um dos meios a partir dos quais os Wajãpi obtinham ferramentas, foi esporádico, sendo um pouco mais frequente a partir de 1850. $\mathrm{O}$ acesso aos bens industrializados no século XIX, no entanto, não se deu prioritariamente pelo contato direto com brasileiros ou franceses, senão pelas transações realizadas através de redes de intercâmbio de bens que se estendiam por toda a região das Guianas, envolvendo povos indígenas e afroamericanos (denominados mekoro, na formulação regional). Tais redes de troca são documentadas desde o século XVI, porém a partir do século XIX

[...] as relações comerciais tomariam uma nova
orientação. A introdução de objetos importados, a
utilização em grande escala dos índios como
fornecedores de produtos silvestres e, eventualmente,
a procura de escravos por intermédio dos próprios
índios alteraram as antigas relações de troca e
comércio (GALLOIS, 1986, p. 195).

A posição que cada população ocupava nessas redes era alvo de disputas, pois quem estava mais próximo a Paramaribo tinha maior acesso aos bens industrializados. Atentando aqui somente às porções das redes que tocam aos Wajãpi: os afroamericanos Boni negociavam com os holandeses na cidade e, por sua vez, forneciam industrializados aos Wayana e Aparai, que trocavam com os Wajãpi ao norte, e estes com os Wajãpi meridionais (no Brasil). 
No século XX, a partir da década de 1960, os Wajãpi no Brasil passaram a ter contatos esporádicos com gateiros e garimpeiros, nas proximidades das bacias dos rios Jari e posteriormente Araguari. Em 1973 a Funai criou uma frente de atração que "deveria 'pacificar' os índios que viviam na região do Amapari” (GALLOIS, 201 1, p. 32) e reuniu famílias wajãpi vindas de diversas localidades em torno de dois postos de atração. À época, estava planejada a construção da Rodovia Perimetral Norte (BR-210), que atravessaria a região em que viviam esse e outros povos indígenas - Wayana, Aparai, Zo'é, Waiwai, Yanomami. Em 1976 o traçado da estrada foi interrompido, e atualmente a rodovia adentra a Terra Indígena (TI) Wajãpi por cerca de trinta quilômetros, ligando-a a Macapá.

Escrevendo nos anos 1980, Gallois (1986) nota que, a partir do processo de fixação das populações indígenas da região em postos de atração, em meados do século $X X$, as trocas entre grupos Wajãpi e grupos de língua caribe cessaram. Passou a ser mais fácil obter os bens desejados com a Funai, através de relações imediatas com os brasileiros. Os Wajãpi vivendo na Guiana Francesa, por sua vez, tornaram-se cidadãos franceses e passaram a contar com benefícios sociais, o que levou a afluxo de bens em suas aldeias.

A TI Wajãpi começou a ser identificada ainda nos anos 1970; foi formalmente delimitada na década seguinte e a homologação de sua demarcação física ocorreu em 1996 (GALLOIS, 2011). Atualmente, vivem na TI Wajãpi mais de 1.200 pessoas, distribuídas em cerca de noventa aldeias, sendo algumas de ocupação permanente e outras habitadas apenas na estação seca.

Contemporaneamente, as relações dos Wajãpi com os bens industrializados, com dinheiro e com a cidade são mais frequentes e ocorrem por diversos caminhos, o que não será examinado neste artigo. Desde a década de 1990, o número de salários e aposentadorias aumentou. Se na década de 1970 apenas três homens wajãpi eram assalariados - esse termo é usado pelos índios para se referir àqueles que ganham ordenados mensais - como funcionários da Funai, nos anos 1990 os mais velhos começaram a receber aposentadorias do Instituto Nacional do Seguro Social (INSS). No início dos anos 2000, foi a vez da turma de professores indígenas passar à condição de assalariada 
(TINOCO, 2000). Posteriormente, outras pessoas começaram a receber soldos mensais: agentes indígenas de saúde, merendeiras, serventes de escola, agentes indígenas de saneamento, entre outros. Quando têm filhos, as mulheres recebem Salário-maternidade, benefício pago às mães indígenas na condição de Seguradas Especiais no INSS. Além disso, as posições assalariadas são bastante disputadas pelas famílias.

Aliada à disponibilidade de salários está a possibilidade de ir com maior frequência à cidade. Algumas famílias, desde o final da década de 2000, têm enviado filhos jovens para completar a escolarização básica em Macapá. As famílias assalariadas, de um modo geral, podem também comprar número maior de objetos na cidade. Esse é o caso sobretudo das famílias dos professores, aqueles mais bem remunerados. Nas aldeias que visitei, as casas dos professores costumam ser as únicas dotadas de televisores, antenas parabólicas e placas solares. Geralmente também são essas famílias que possuem motores de popa para voadeiras.

\section{Os Wajãpi e suas vestes}

Parte-se de uma descrição feita no início dos anos 1990 por Dominique T. Gallois (1992) sobre a ornamentação corporal dos Wajãpi:

[...] a decoração corporal inclui um conjunto limitado de itens: a tanga ou saia de pano vermelho, as fieiras de miçanga (que substituíram as antigas bandoleiras de fios de algodão), a coroa de plumas de tucano (akã'neta) e a pintura corporal em suas três variantes urucum, jenipapo e resina -, muitas vezes usadas conjuntamente. São esses, segundo os Waiãpi, os elementos normais da vestimenta diária. É claro, porém, que nem todos se vestem "ao completo" no cotidiano. Os colares incomodam em tarefas da roça e na caça; o ritmo dos trabalhos de subsistência às vezes compromete as sessões de pintura... Observei que os que mais cuidam de sua aparência são rapazes e moças solteiras, que ostentam quase sempre no rosto motivos kusiwa, com resina ou jenipapo. Por outro lado, as mães procuram sempre adornar seus filhos pequenos 
com os motivos kusiwa e os revestem com camadas de urucum após cada banho, de manhã e à tarde. ${ }^{5}$ Os homens adultos são pintados pelas esposas, sem que existam períodos específicos para essa atividade, essencialmente lúdica.

Por ocasião das festas de caxiri, homens e mulheres retiram de seus cofos [...] pagara, pano vermelho novo para tanga ou saia; os homens colocam seus akã'neta e, às vezes, cedem-nos a suas esposas. Dos cofos são também retiradas, dentre outras coisas, pesadas fieiras de miçangas, usadas como colares, bandoleiras, tornozeleiras e joelheiras.

$\mathrm{Na}$ véspera de uma festa, todos cuidam especialmente de sua pintura corporal, exibindo elaboradas composições de kusiwa, aplicadas com jenipapo sobre um fundo de urucum (GALLOIS, 1992, p. 222-223).

Ainda sobre as pinturas corporais com jenipapo, é possível notar estilos masculinos e femininos, de acordo com a antropóloga. Observase também a existência de uma oposição entre adornado/não adornado no conjunto da decoração corporal dos Wajãpi e

[...] a profusão de decoração marca a plenitude da pessoa. Assim, por ocasião das festas de caxiri, adultos e crianças se paramentam com tangas compridas e outros elementos do vestuário, raramente usados no dia-a-dia. [...] São nessas ocasiões, enfim, que podemos reconhecer mais facilmente a situação individual de cada membro do grupo, quanto a sua origem e, sobretudo, seu estado pessoal. A ausência de decoração marca os estados liminares (parto, menstruação, resguardo e luto), que exigem das famílias atingidas um comportamento discreto e um afastamento da vida social (GALLOIS, 1992, p. 224).

A partir dessa descrição, tratarei do modo como os Wajãpi se vestem atualmente. Permanece sendo notada a distinção entre uma pessoa estar ou não adornada. Além disso, o uso de certos itens, guardados em malas e não mais em cofos, restringe-se apenas a algumas ocasiões. Tangas e saias de pano vermelho são de uso corrente, as miçangas são bastante apreciadas, e as pinturas com

\footnotetext{
${ }^{5}$ Kusiwa são “[...] padrões gráficos que representam, de forma sintética e abstrata, partes do corpo ou da ornamentação de animais e de objetos" (GALLOIS, 2002, p. 14). Ver também Pesquisadores e Professores Wajãpi (2009).
} 
urucum, resinas perfumadas (sipy) e jenipapo revestem corpos de muita gente. Por outro lado, não se pode mais dizer que "a decoração corporal inclui um conjunto limitado de itens", pois muitos outros são usados contemporaneamente: roupas para bebês, calcinhas, sutiãs, maquiagem, batons, esmaltes, chinelos, camisetas, casacos, brincos, cortes de cabelo imitando jogadores de futebol ou cantores de música sertaneja, enfeites de cabelo, presilhas... Há ainda as roupas usadas somente para visitas à cidade, como calças compridas e bermudas (para homens e algumas poucas mulheres), vestidos e saias, camisetas, tênis, meias, óculos de sol. Nas aldeias que visitei foi possível observar que homens e mulheres usam tangas e saias de tecido industrial vermelho, denominadas pelo termo que nomeia o tecido: kamisa pirã $\tilde{a}^{6}$. Algumas mulheres alternam as saias vermelhas com outras de tecido estampado, designadas, por sua vez, kamisa wiri. Assim como as saias vermelhas, seu tecido não deve ser muito fino, dando-se preferência aos panos de algodão, que se fixam melhor aos quadris. Disseram-me que o uso de kamisa wiri, bem como o de sutiãs, foi aprendido com mulheres wajãpi da Guiana Francesa, residentes no conjunto de aldeias denominado Camopi, com as quais os Wajãpi do Amapá retomaram o contato no início dos anos 1990. Atualmente na TI Wajãpi muitas mulheres apreciam panos estampados e procuram adquirir tecidos diferentes umas das outras. Da parte dos homens, o uso de kamisa tawa (tangas de tecido alaranjado) é mais raro e é também associado ao Camopi. Conforme apontou Gallois (1992), algumas pessoas costumam reservar kamisa novos e longos para as ocasiões festivas.

Mencionei anteriormente que algumas mulheres wajãpi passaram a usar sutiãs por influência das mulheres residentes em Camopi. De um modo geral, tal vestimenta é reservada para situações em que se pode deparar com não índios, como nas aldeias às margens da rodovia Perimetral Norte e em suas imediações, ou ainda nas escolas e cursos. Nem todas as mulheres, contudo, usam essa peça de roupa e nas

\footnotetext{
6 As tangas de tecido vermelho são ou foram também usadas pelos grupos indígenas da região das Guianas, e são igualmente designadas kamisa. Assim escreve Lúcia Van Velthem (2003, p. 281, nota 47): "Essa indumentária e sua nomenclatura são antigas, sendo descritas por Stedman em fins do século XVIII [...] nos seguintes termos: "the only dress worn by these Indians (os Carib) consists os a slip of black or blue cotton worn by men and called camisa"”. Ipirã, em língua wajãpi, designa a cor vermelha.
} 
aldeias distantes da estrada, seu uso é mais raro. De todo modo, junto com os bustiês esportivos, os sutiãs compõem o vestuário cotidiano de algumas mulheres mais jovens, como é o caso daquelas que não estão amamentando7. Quando faz frio pela manhã, ou quando vão à roça arrancar mandioca ou carregar cestos cargueiros, algumas mulheres vestem-se com camisetas velhas. Entre os homens, observei que muitos usam camisetas diariamente, e em conversa com alguns deles, disseram-me que já se acostumaram com essa peça de roupa ${ }^{8}$. Quando saem para caçar, muitos portam jaquetas esportivas; vi somente um homem trajando bermuda: trata-se de um homem adulto que se mudou para a TI Wajãpi ao se casar, vindo de uma aldeia wajãpi na Guiana Francesa onde não se usam mais tangas. Mesmo esse homem, porém, usou tanga na maior parte do tempo em que estive na aldeia em que mora.

No caso dos bebês, é recorrente encontrá-los completamente vestidos, até mesmo com meias e gorros de lã sintética - sobretudo nas aldeias próximas à estrada. As mães de bebês alegam protegeremnos do frio e da chuva, para que não peguem pneumonias ou gripes.

Meninas pequenas, que já andam sozinhas, usam calcinhas; algumas também usam kamisa pirã ou kamisa wiri. A idade para começar a usar saias e tangas, aliás, parece variar de família para família, de aldeia a aldeia. É comum os meninos pequenos andarem apenas com o cinto ( $k o^{\prime}$ â) usado para prender a tanga, mas ainda sem trajar tal vestimenta 9 .

O uso de miçangas varia muito: há quem use muito e quem raramente se adorne com esse tipo de enfeite. No dia a dia algumas mulheres usam pequenos colares, joelheiras, pulseiras e tornozeleiras feitos dessas contas. Cintos (para mulheres), colares de muitas voltas (para mulheres) e bandoleiras (para homens) são usados principalmente

\footnotetext{
${ }^{7}$ Flora Cabalzar (1997) nota que o formato dos seios é usado pelos Wajãpi como medida de maturação e envelhecimento das mulheres. As mulheres adultas com dificuldades para engravidar passam muito tempo sem amamentar e, segundo elas, suas mamas murcham, assemelhando-se aos seios de mulheres velhas.

${ }^{8}$ Neste artigo, abordarei apenas superficialmente a noção de acostumar e sua implicação para o uso de roupas urbanas pelos Wajãpi. Tratei desse ponto em minha dissertação (PAULA, 2015).

${ }^{9}$ Quando a oferta de panos não era tão grande, a puberdade marcava o início do uso de tangas, sendo o aparecimento de pelos pubianos o indicador para que rapazes trajassem tal veste. As saias femininas eram usadas após a menarca da garota (ROSALEN, 2005, p. 83-84).
} 
em festas, nas visitas a outras aldeias ou nos cursos e reuniões nas escolas. Como nota Gallois (1992), enfeitar-se excessivamente pode atrapalhar a pessoa nos trabalhos da roça; ainda assim, é possível ver jovens moças usando largas joelheiras de miçanga durante a colheita do roçado e ao carregar cestos cargueiros repletos de mandioca. Rapazes e moças solteiras são, em geral, os mais enfeitados.

Há cores de miçanga que se destacam na preferência dos Wajãpi: o azul médio (-sovã), em primeiro lugar, sucedido por tons como kure reposi ("fezes de papagaio", que corresponde a um tom azul claro ou turquesa), branco (-si), preto (-pijô), amarelo (-tawa). Laranja, vermelho (-pirã), marrom e verde (-jaky) são cores de miçanga também usadas, mas menos compradas ou pedidas. As contas transparentes/brilhantes (isyrynyny - termo que também qualifica o brilho das estrelas e do ouro) são também apreciadas.

Todas as pessoas usam chinelos de dedo. Em algumas aldeias, pude notar que as cores das sandálias acompanham as cores das miçangas. Assim, o azul médio é a tonalidade mais procurada, seguido pelo azul claro, o turquesa, o amarelo e o branco. Cor de rosa é tonalidade usada somente por mulheres.

Nos dias atuais são poucos os homens que mantêm seus cabelos longos, preferindo cortá-los curtos, ao estilo da maioria dos amapaenses não indígenas, ou inspirando-se nos cortes e penteados de pessoas famosas, como jogadores de futebol e cantores de música sertaneja. Outrora os homens wajãpi traziam cabelos longos e passaram a cortá-los após a chegada da Funai, nos anos 1970. Muitos contam têlo feito para não ser reconhecidos como indígenas em Macapá, dado o preconceito que sofrem na cidade. Atualmente, porém, jovens solteiros ou recém-casados disseram-me cortar os cabelos curtos por ser a preferência das mulheres jovens. Estas, por sua vez, parecem ser menos inovadoras no que diz respeito aos penteados ${ }^{10}$. No entanto, um velho wajãpi me disse certa vez que não gosta do modo como suas filhas e netas repartem os cabelos de lado, prática recente. Não é incomum, além disso, ver jovens de ambos os sexos com mechas loiras.

\footnotetext{
${ }^{10}$ Com relação ao maior conservadorismo das mulheres no modo de se vestir, para os Urarina na Amazônia peruana, ver Walker (2013, p. 56-57).
} 
As pinturas corporais continuam a ser usadas. O urucum reveste corpos com bastante frequência: as mulheres costumam pintar-se com essa tintura quando vão à roça e os homens, quando vão caçar. As pinturas de jenipapo, com padrões kusiwarã, são feitas por quem preparou ou obteve tintura desse fruto. Pintar a si, aos filhos, maridos, irmãos é uma ação "essencialmente lúdica", não havendo "períodos específicos para essa atividade" (GALLOIS, 1992, p. 222). Resinas perfumadas também são usadas em algumas ocasiões. Além dessas pinturas corporais, há também, nos dias de hoje, maquiagem (karai sipy'yy) e batons. Lápis e sombras coloridas são usados para compor padrões nas faces de homens e mulheres. As mulheres, sobretudo as mais jovens, fazem maquiagens mais elaboradas e disseram-me gostar da ampla gama de cores dos estojos de sombra. Uma mulher contoume que acha bonito usar diversas cores para colorir seu rosto, pois as maquiagens permitem-na pintar-se com as várias tonalidades dos pássaros. Raramente aplicam sombra nas pálpebras, à maneira das não índias. Esse é um uso que os homens jamais fazem, sendo associado ao estilo feminino. Batons e esmaltes de unha, usados por algumas mulheres, são também exclusividades femininas.

\section{Imitação: pegar o jeito de outras gentes?}

Conversando com um agente indígena de saúde, perguntei a ele por que diversos rapazes cortavam seus cabelos como os de Neymar. Sua resposta foi a seguinte: "Eu acho que é porque nós, Wajãpi, pega logo jeito de viver dos outros". E explicou-me que os jovens viam o jogador pela televisão e queriam imitar seu penteado. Quando eu quis saber se os rapazes assim cortavam seus cabelos para poder jogar melhor futebol, ele hesitou em dizer que sim. Numa outra conversa, dessa vez com um homem mais velho, avô de vários netos, ele me disse desaprovar o corte de cabelo de um de seus genros. Segundo esse senhor, os cabelos do marido de sua filha eram como os de Neymar porque o jovem gostava muito de jogar futebol. "Sou jogador", diria ele.

Em outra aldeia, numa conversa com uma mulher adulta, ela me contava de um recente encontro de mulheres indígenas do Amapá do 
qual participara. Dizia-me que não era boa falante de português, e por esse motivo compareceu ao encontro usando sua saia de pano vermelho e sandálias de borracha. Ainda segundo ela, as mulheres que falavam bem o português usavam, no tal encontro de mulheres, calça jeans e mochila. Caso ela também fosse boa falante de português, teria usado calça jeans e mochila ${ }^{11}$.

Numa terceira aldeia, depois de uma beberagem de caxiri, os jovens adultos ligaram o aparelho de som - o "gravador", como dizem - e começaram a dançar ritmos populares na região: melody, technobrega, sertanejo. Foi nesse momento que começaram a aparecer alguns itens de vestuário que não são comumente avistados nas aldeias, e que em geral ficam guardados em malas ou sacolas para uso urbano: óculos de sol, camisas, fones de ouvido. Além dos ritmos populares no Amapá, havia ainda no pendrive, canções que me apresentaram como lambadão, música dos xinguanos. Conforme me explicou um professor que esteve no Parque Indígena do Xingu há alguns anos, aprenderam a dançar esse tipo de música por lá e ensinaram os outros a dançar, em reuniões de caxiri. Naquela aldeia, esse é um ritmo bastante popular. Certo homem foi-me apontado como excelente dançarino do lambadão dos xinguanos. Contaram-me que há uns anos esse mesmo homem costumava vestir-se com calça, camisa e tênis quando ia dançar no gravador, isso é, dançar embalado por músicas tocadas no aparelho de som. Em outro momento, ainda na mesma reunião de caxiri, um homem explicou-me sobre as roupas que apareceram e a música tocada no aparelho de som. Trajando uma camisa aberta e ouvindo música pelos fones de ouvido conectados a seu celular, tal homem passou a me explicar que eles seguem "os dois caminhos": fazem festas com cantos wajãpi, mas também ouvem músicas dos karai kõ (não índios), pois estão dentro do Brasil12. Complementou a explanação ressaltando que não podem ir somente pelo caminho dos karai kõ, porém tampouco

\footnotetext{
${ }^{11} \mathrm{O}$ uso de calças por mulheres wajãpi nas cidades, ao menos na época de minha pesquisa de campo, parecia ser alvo de debates, não sendo muito popular. Isso se relaciona à vergonha das mulheres em mostrar a parte superior de suas pernas a homens que não sejam seus maridos. Trato desse tema em outro artigo (PAULA, 2016).

12 Gallois (2005) já registrou a enunciação dos Wajãpi de que querem seguir “dois caminhos”, o wajãpi e o dos não indígenas. A antropóloga escreveu sobre isso no contexto do processo de patrimonialização das artes gráficas e orais wajãpi pela Unesco em 2003.
} 
podem ignorá-lo. Retomo mais adiante a imagem dos "dois caminhos".

O que gostaria de indagar, a partir dessas três imagens, é se há, para os Wajãpi, uma relação entre as roupas (e penteados) e os comportamentos adquiridos pelo seu uso. Ou, como seria mais legítimo perguntar aos Wajãpi: imitar Neymar faz o rapaz pegar seu jeito? Usar calça jeans faz uma mulher falar bem a língua portuguesa? Essas perguntas, como já deve ter ficado claro para o leitor etnólogo, fundamentam-se em certo entendimento do que sejam corpos na América do Sul indígena. Procedo, a seguir, a uma breve explanação do que alguns amazonistas têm escrito sobre a relação entre corpos e roupas. Em seguida, fundamento minhas questões nas reflexões dos Wajãpi e de algumas pesquisadoras sobre a imitação.

A literatura sobre corpo e fabricação corporal na América do Sul indígena é demasiadamente extensa para proceder a uma revisão. Cumpre lembrar que é central para a noção de pessoa ameríndia (SEEGER, DA MATTA e VIVEIROS DE CASTRO, 1979). É no "conjunto de maneiras e processos que constituem os corpos", que se situa "o lugar da emergência da diferença" (VIVEIROS DE CASTRO, 2006, p. 388) no monoculturalismo ameríndio. Ao explicar o que intitula de perspectivismo ameríndio, Eduardo Viveiros de Castro compara corpos a roupas: "[...] os animais são gente, ou se vêem como pessoas. Tal concepção está quase sempre associada à idéia de que a forma manifesta de cada espécie é um envoltório (uma 'roupa') a esconder uma forma interna humana [...]" (VIVEIROS DE CASTRO, 2006, p. 388). O que não significa que roupas sejam aparências a recobrir essências. Muito pelo contrário.

Trata-se menos de o corpo ser uma roupa do que uma roupa ser um corpo. Não esqueçamos que nessas sociedades inscrevem-se na pele significados eficazes, e se utilizam máscaras animais (ou pelo menos conhece-se seu princípio) dotadas do poder de transformar metafisicamente a identidade de seus portadores, quando usadas no contexto ritual apropriado. Vestir uma roupa-máscara é menos ocultar uma essência humana sob uma aparência animal que ativar os poderes de um corpo outro. [...] [A]s roupas que, nos animais, recobrem uma 'essência' interna de tipo humano não são meros disfarces, mas seu equipamento distintivo, dotado das afecções e 
capacidades que definem cada animal (VIVEIROS DE CASTRO, 2006, p. 393-395).

Entre os ameríndios, roupas são corpos, no sentido de que agenciam determinados comportamentos e demarcam pontos de vista. Esse argumento é estendido por Aparecida Vilaça (2000), ao lidar com o uso de roupas de não índios pelos Wari'. Sua hipótese é de que:

[...] não há uma diferença substantiva entre as roupas animais usadas pelos xamãs e pelos próprios animais (quando se mostram aos índios), os adereços corporais propriamente indígenas, e as roupas manufaturadas trajadas por índios em contato com Brancos. São todos igualmente recursos de diferenciação e de transformação do corpo [...] (VILAÇA, 2000, p. 60).

Levando adiante essa hipótese, Elizabeth Ewart lê seus dados de campo entre os Panará na mesma chave:

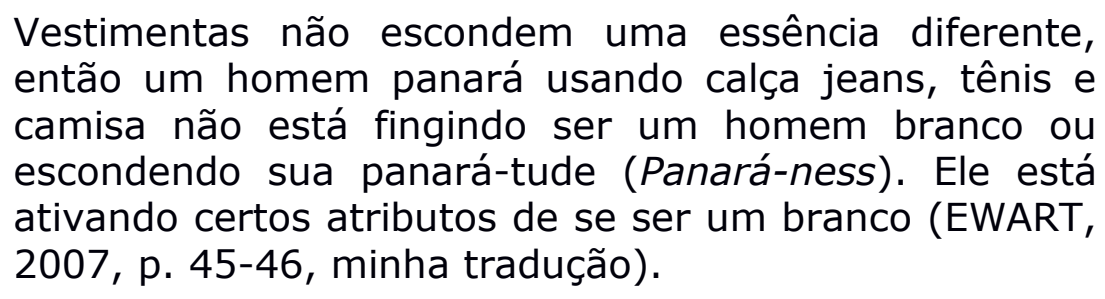

De acordo com sua análise, há situações em que se deseja ativar capacidades de não índios, e nesses casos veste-se com os trajes de branco. Já em outras ocasiões, como nas relações sexuais entre cônjuges, não se busca os atributos dos brancos.

Com essa digressão, quis pontuar que existem análises que colocam em paralelo práticas de fabricação corporal a partir de roupas de não índios e práticas de fabricação corporal em que certas máscaras, roupas, inscrições podem "transformar metafisicamente a identidade de seus portadores" (VIVEIROS DE CASTRO, 2006, p. 393) em contextos adequados. A meu ver, é possível fazer esse tipo de leitura quando uma mulher wajãpi insistiu que se ela falasse bem português usaria calça jeans e mochila durante o encontro de mulheres indígenas. A destreza na língua portuguesa e o uso de calças jeans e mochila, porém, não me parece ser algo que minha interlocutora atribui necessária ou exclusivamente aos karai kõ, não índios. As mulheres das etnias 
indígenas do município de Oiapoque (AP), bem como algumas mulheres do Parque Indígena do Tumucumaque, sempre de acordo com minhas interlocutoras wajãpi, também usam calças jeans, mochilas, sobrancelhas pintadas. Num encontro de mulheres wajãpi em que atuei como assessora, muitas mulheres ressaltavam a habilidade de falar português (presumivelmente sua língua materna) de uma certa cacica do Oiapoque. Quero apenas ressaltar que as imitações dos usos de roupas não passam somente pela imitação de não índios - e "não índios" já constitui em si uma gama enorme de modas, roupas, habilidades, cujas diferenças e sutilezas os Wajãpi têm aprendido a reconhecer -, mesmo quando o objeto ou a habilidade em jogo nos parece eminentemente urbano $^{13}$. Calças e língua portuguesa são também, aos olhos das Wajãpi, atributos de mulheres indígenas de outras etnias. Bem como o lambadão, que é dos xinguanos.

No caso das boas falantes de português que se vestem com calças jeans, conforme eu argumentei, creio ser possível falar num mecanismo de produção de corpos-capacidades que conjuga aquilo que entendemos por "aparência" e "habilidades" - ou jeito. Usar mochila e calça é ter um corpo que fala bem português, negocia, faz política com(o) os não índios. É esse também o caso dos meninos e rapazes que cortam seus cabelos à Neymar? Imitar o cabelo do futebolista relacionase a jogar bem o esporte? Algumas pessoas me responderam essa pergunta afirmativamente e outras, negativamente. Antes de seguir com a resposta mais imediata para a questão "imitar Neymar implica em adquirir seu jeito?", será preciso um desvio às considerações dos Wajãpi e de suas antropólogas sobre a imitação.

\section{Imitação}

Wã'ã, explicam os pesquisadores e professores wajãpi (2009, p. 79), pode-se traduzir por "imitar, copiar, reproduzir, representar, fazer

\footnotetext{
${ }^{13}$ Em seu livro, E. Ewart (2013b) apresenta as roupas que as mulheres panará aprenderam a costurar com as mulheres kisêdjê e a comprar igual às de mulheres kayapó. Também ali as roupas compradas em cidades são modas de outras mulheres indígenas, kayapó; e nesse caso específico, são roupas confeccionadas de acordo com um modelo que é exclusivamente kayapó.
} 
como". Joana C. de Oliveira (2012, p. 185) explica o ato de imitar como sendo uma "estratégia fundamental na apreensão e circulação de saberes": foi por imitação que os ancestrais dos Wajãpi aprenderam os padrões gráficos que utilizam (GALLOIS, 2012); assim também aprenderam os cantos e danças das festas com outras gentes nos tempos primordiais (GALLOIS, 1988). É imitando seus gritos que os caçadores atraem as caças (OLIVEIRA, 2012, p. 97).

Os pesquisadores wajãpi ainda dão os seguintes exemplos:

Para nós, Wajãpi, a'ãga é imitação. Por exemplo, imitação de festas. Nós imitamos peixe quando dançamos pakuwasu (pacu grande). Nós imitamos japu na festa do japu, etc. [...] Não imitamos somente essas coisas, também imitamos esturro de onça e cantos dos pássaros.

Também imitamos a voz dos pássaros que nós ouvimos nas outras aldeias. A gente também imita canoa feita por outro grupo e as casas deles. Além disso, nós imitamos algumas pinturas corporais de outros grupos, porque nós achamos bonitas, por isso imitamos. Quando a gente está começando a aprender a falar a língua portuguesa, nós imitamos os Karai kõ para aprender rápido (PESQUISADORES WAJÃPI, 2008, p. 25).

Nos dias de hoje, explica Dominique T. Gallois, wa'ã é expressão usada pelos Wajãpi

[...] para todo processo de duplicação, como foto, filmagem, reprodução em papel, representação corporal, tudo o que torna visível, replica uma experiência num outro tempo, num outro lugar. Nessas situações, o que circula são ã'ãga (traduzido como "imagens") que dispersam os elementos vitais de quem é fotografado, filmado ou imitado. E isso, obviamente, é muito perigoso, pois se atrai o olhar de quem é imitado (GALLOIS, 2012, p. 39).

A imitação (wa'â), desse modo, replica uma imagem (ã'ãga) que não é só imagem, mas algo que carrega o princípio vital (-‘â) do fotografado ou daquele que se imita (GALLOIS, 2012; PELLEGRINO, 2008; PESQUISADORES WAJÃPI, 2008). A dispersão dos componentes da pessoa e seu consequente estado de leveza, como argumentou Gallois 
(1988), é muito perigoso.

Ademais, os excessos de imitação podem ser arriscados e levar a transformações corporais. Joana C. de Oliveira (2012), por exemplo, apresenta em sua tese uma narrativa em que, ao imitar os trejeitos e a pintura do guariba, um homem virou guariba. O mesmo aconteceu com outro antepassado que se pintou com machas como as da onça e imitou sua forma de caminhar: virou onça. Imitar insistentemente o corpo e os modos do outro pode, portanto, conduzir a uma transformação, o que faz Oliveira (2012, p. 186) argumentar que wa'ã seja "um modo de reviver uma experiência", ou, sugiro, de experimentar outro corpo, outro ponto de vista. Não parece ser por outro motivo que o uso excessivo de roupas advindas da cidade pode ser perigoso: há o risco de a pessoa se acostumar com seu uso, deixando de querer se pintar com urucum. Assim como nota Cesar Gordon sobre as reflexões dos Xikrin relativas ao consumo excessivo de mercadorias, o uso exagerado de roupas parece ser entendido pelos Wajãpi como transformações corporais que podem torná-los "parecidos demais com os brancos, pela modificação gradativa do corpo e dos afetos" (GORDON, 2006, p. 403).

Voltamos aos cabelos de Neymar e ao caxiri em que, dançando no gravador, algumas pessoas passaram a trajar camisas e óculos de sol. Conversando com o homem que disse ser famoso por dançar bem o lambadão, ele contou que há alguns anos costumava se vestir com sapato, calça e camiseta na hora de dançar. Tudo isso, disse-me uma interlocutora daquela aldeia, era de brincadeira (jimorara) ${ }^{14}$. Outro morador da aldeia, alguns dias depois, contou-me sobre as brincadeiras (jimorara) de imitação realizadas nas reuniões de caxiri, sobretudo quando as pessoas já atingiram o estado de embriaguez ( $-k a a^{\prime} o$ ). Antigamente, relatou-me, os homens imitavam o "grito das caças" e os cantos dos inimigos. Atualmente, há apenas seu sogro de "adulto" expressão usada por alguns Wajãpi para se referir aos mais velhos naquela aldeia, e os mais jovens não sabem imitar os gritos dos animais que caçam. Prosseguiu explicando que ainda há brincadeiras de imitar, mas a referência da imitação mudou. Quem é mais jovem "só imita do

\footnotetext{
${ }^{14}$ Ver Cabalzar (1997, p. 103) sobre as brincadeiras como essenciais a "uma performance dialógica ou conversacional" entre os Wajãpi.
} 
karai kõ [não índio]. Dança, conversa, como gay anda, conversa do gay"15. De fato, ouvi muitas pessoas cantando e conversando entre si em língua portuguesa quando já estavam embriagadas (-ka'o). Perguntei a esse homem, então, se a imitação que atualmente fazem dos não índios - falar português, vestir-se com camisetas e calças para dançar "no gravador", imitar o jeito dos karai kó falar - era de mesmo tipo das imitações que os mais velhos costumavam fazer, reproduzindo os gritos dos animais. Meu interlocutor se mostrou reticente com a comparação, mas, por fim, concordou tratar-se da mesma coisa.

Vale a pena registrar uma comparação com outro contexto ameríndio, em que a imitação dos não índios também pode se relacionar à aprendizagem e à mudança temporária de perspectiva. Els Lagrou, trata do "brincar de branco" entre os Kaxinawa, atividade que é realizada em diversas situações. Segundo sua análise, o "brincar de banco" constitui tanto o riso do poder quanto a possibilidade, numa "teoria relacional da identidade, [...de o] outro [...] se tornar igual a nós mesmos e ao mesmo tempo [...] se tornar outro" (LAGROU, 2006, p. 73). De acordo com a antropóloga, as brincadeiras de branco desse povo de língua pano são atividades em que se pode "experimentar o ponto de vista do outro e [...] incorporar este outro dentro da pessoa, sem aniquilá-lo nem deixar de ser o que se é" (LAGROU, 2006, p. 76). Em suma, para formular como os Wajãpi, trata-se de seguir dois caminhos $^{16}$.

Gostaria de sugerir, a partir de alguns dos exemplos elencados acima, que é possível estabelecer uma aproximação do material wajãpi com as sugestões de Vilaça (2000), Ewart (2007) e Lagrou (2006)

\footnotetext{
${ }^{15}$ Noto que em outras aldeias, em reuniões de caxiri, vi homens e mulheres imitando animais de caça, bem como imitando outros idiomas, ao reproduzir a prosódia das línguas wayana e francesa.

${ }^{16}$ Essa possibilidade encontrada por diversos povos amazônicos de "seguir dois caminhos", ou "ter dois corpos simultâneos" (VILAÇA, 2000, p. 57) parece-me dizer respeito ao que José Kelly Luciani (2016) sintetizou recentemente sob o nome de "teoria da antimestiçagem". Trata-se de um princípio teórico e prático amazônico (ou talvez pan-ameríndio) em que, para os índios, tornar-se "branco" ou "civilizado" é sempre um processo necessariamente incompleto. Não se deseja virar branco de vez, mas manter a possibilidade de trânsito entre ser "branco" e não o ser; estamos diante de uma teoria que combina culturas, e não as funde, aniquilando, assim, a diferença (como fazem, de acordo com Kelly, as teorias latino-americanas da mestiçagem). Ver ainda as discussões de Nunes (2010) sobre a noção de mistura para os Karajá de Buridina, que em muito se relaciona à dos Wajãpi, com a diferença de que para os Wajãpi (bem como para os Wari' sobre quem escreve Vilaça [2000]), a possibilidade de se casar com não índios não é bem vista e é evitada.
} 
apresentadas sinteticamente. Creio ser legítimo afirmar que, ao menos em alguns casos, os usos de certas roupas, cortes de cabelo e ornamentos pessoais relacionam-se à fabricação de corpos com determinadas capacidades e comportamentos: falar bem português, jogar bem futebol, dançar lambadão habilidosamente. Registre-se, contudo, que muitas vezes meus interlocutores mostravam-se reticentes em elaborar essa reflexão.

\section{Imitação: dinâmicas de circular objetos}

O segundo percurso trilhado na análise das considerações dos Wajãpi sobre imitação pretende estabelecer diálogo com a bibliografia amazonista dedicada ao estudo da circulação de mercadorias entre povos indígenas (por exemplo: DAL POZ, 2004; GORDON, 2006). Conforme é possível depreender de diferentes etnografias sobre essa questão, há "dois princípios institucionais" (DAL POZ, 2004, p. 185) operando na circulação desses bens: por um lado, há o "consumo diferencial" (GORDON, 2006), obra daqueles que buscam marcar suas posições de liderança e chefia através dos bens adquiridos; por outro, nas relações intra-aldeãs, busca-se negar esse tipo de diferença por meio da produção de parentes e da generosidade.

Interessada em compreender como se processava a circulação das mercadorias pelas diferentes aldeias, bem como em entender os critérios valorativos que orientavam as compras dos Wajãpi, chamou-me a atenção que muitas meninas pequenas eram trajadas por suas mães com calcinhas com babados. Fui notando, também, que havia muitas roupas e objetos que diversas pessoas, habitantes de aldeias distintas, possuíam: o mesmo modelo de relógio digital, um mesmo estilo de blusão de times de futebol - os times mudavam -, os mesmos enfeites de cabelo etc. Curiosa, passei a perguntar às pessoas o motivo para que muitas tivessem objetos parecidos. Indagadas, muitas delas me explicavam a existência de coisas semelhantes da seguinte maneira: uma mulher foi a Macapá e comprou calcinhas com babados para suas filhas. De volta para a aldeia, as outras mulheres viram tal vestimenta e gostaram. Assim, passaram a imitar, e vestir suas filhas da mesma 
maneira.

Diversos são os exemplos de modas que foram imitadas e de objetos cuja circulação os Wajãpi me explicaram desse modo. A fim de não multiplicar em demasia os exemplos, cumpre notar que a lógica da imitação abrange coisas tão distintas como o uso espraiado de um mesmo modelo de relógio de pulso, o uso de enfeites de cabelo semelhantes, o uso de sutiãs, o uso de blusões de futebol, modelos de panela até o hábito recente de enviar filhos para concluir a educação escolar básica na cidade de Macapá.

É o caso também da prática de comemorar aniversários. Contoume um morador da aldeia Kwapo'ywyry que aprendeu a fazer festas de aniversário com um motorista não indígena que faz fretes para Macapá. Explicou-lhe que se deve comprar um bolo, refrigerantes e balões. $O$ homem wajãpi, então, decidiu comemorar o aniversário de seu filho mais novo. A partir daí outras pessoas em aldeias próximas passaram a comemorar aniversários fazendo bolos e reservando dinheiro para comprar refrigerantes na comunidade rural mais próxima na rodovia Perimetral Norte. Há algumas coisas que somente uma pessoa conseguiu comprar, mas que outras já se organizam para imitar: apenas um homem possui automóvel, mas, conforme me disseram, outros assalariados estariam se juntando para comprar um carro. Algumas pessoas inclusive estavam já fazendo os cursos de autoescola em Macapá. Esses são casos em que os Wajãpi apontam o iniciador de determinada moda, mas há diversos outros usos espraiados que têm um iniciador hipotético, ninguém sabendo ou recordando exatamente quem foi. De todo modo, a ação é sempre explicada nesses termos: alguém fez pela primeira vez, outra pessoa o imitou, os outros foram imitando até todos fazerem igual.

Mais uma vez no exercício de justaposição de meus dados com outros estudos sobre povos ameríndios, creio ser possível pensar que estamos diante de uma lógica do tipo iniciador-seguidores, descrita para vários contextos sul-americanos. Exemplo famoso é o do tenatãmõ araweté, que

[...] significa "em primeiro lugar", "o que segue à frente", "o que começa". [...] A situação de tenetãmõ se seguem as que estão ipite re, no meio ou entre-dois, 
e as tacipe, que estão atrás ou por último. O líder Araweté, assim, é o que começa, não o que ordena; o que segue à frente, não o que fica no meio.

Toda e qualquer empresa coletiva Araweté supõe um tenetãmõ: não existe começo inocente, acordo "comum" em que todos estejam na mesma relação com a tarefa. Uma coisa não começa se não houver alguém em particular que a comece. Mas, entre o começar do tenetãmõ, já de si relutante, e o prosseguir dos demais, sempre é posto um intervalo, vago mas essencial: a ação inauguradora é respondida como se fosse um pólo de contágio, não uma abertura legitimadora ou exortativa: e, não obstante, espera-se por ela (VIVEIROS DE CASTRO, 1986, p. 302-303).

No caso araweté, não é apenas no caso da chefia ou das atividades produtivas que tal lógica do iniciador se aplica:

A aldeia Araweté parecia passar por ciclos, desde no
que tocava a modas superficiais (uma canção, uma
brincadeira invadiam os dias), até esferas sociológicas.
Assim, por exemplo, se um jovem se casava, logo em
seguida toda a aldeia se punha a ensaiar ligações (o
mais das vezes temporárias) entre os meninos e
meninas na faixa dos 10-12 anos (VIVEIROS DE
CASTRO, 1986, p. 303, nota 17).

O modo como os Wajãpi me explicavam certas modas, dessa feita, me parece comparável ao que Eduardo Viveiros de Castro notou entre os Araweté: toda ação tem um iniciador, que é seguido pelos demais. Entre os Wajãpi, há sempre alguém que inicia uma determinada moda, e essa pessoa tem sua ação imitada pelos demais.

Conforme comentei, o acesso das famílias wajãpi a salários e bens não é igualmente distribuído. Comprar o que os outros têm adquirido, assim, pode ser cada vez mais difícil para algumas famílias. Quando o iniciador de uma moda é um assalariado, é possível que outras famílias não possam imitá-lo. Essa possibilidade parece preocupar alguns de meus interlocutores. Um deles assim ponderou:

[Tem] Wajãpi assalariados, tem Wajãpi que não são assalariados, tem Wajãpi que sabe ler e escrever e tem os que são analfabetos. Então, eu disse que na aldeia não existe desigualdade social, mas na verdade existe. Só que os Wajãpi, não passam fome. Todos caçam, pescam, fazem roça para plantar para sustentar suas 
famílias. Eles não sofrem com essa desigualdade que existe na aldeia, pois já têm terra para morar, para fazer plantação, para caçar e pescar. Não sei se isso vai continuar assim mesmo (Depoimento obtido por escrito em maio/2014).

\section{Fazer preconceito e os limites da disputa}

Fazer disputa, ou fazer preconceito, pelo que entendo, é uma dinâmica que se articula estreitamente à lógica dos iniciadores e seguidores, seja no contexto da alocação mais recente de salários e benefícios sociais, seja anteriormente. Se o dinheiro acirra a disputa, ou torna a imitação impossível e muito custosa - já que o acesso ao dinheiro não é igualmente distribuído - a algumas famílias, é algo que não tenho como responder por ora. Foi sobretudo nas conversas sobre os jovens que estudam na cidade que as pessoas me falavam sobre a disputa.

Duas mulheres me disseram, certa vez, que os jovens estudantes da cidade fazem preconceito com os demais. Ao voltar às aldeias nas férias escolares, usam camisetas de marcas, ostentam as coisas que têm: celulares, tênis, tablets, muitas roupas etc. Fazer preconceito foi uma das traduções para jirõarõa, termo também traduzido como disputa, inveja, desigualdade. Ainda sobre os estudantes na cidade, outros homens me falaram sobre disputa: aqueles que vivem em Macapá são os primeiros a fazer alguma coisa, daí os outros "querem alcançar" e "não querem ser deixados para trás". Isso acontece com as roupas de marca, os tênis, os celulares, tablets, computadores.

Fazer preconceito ou inveja, contudo, não se refere somente às roupas compradas na cidade, ou mesmo a outros bens adquiridos em Macapá, mas a um conjunto de ações que uma pessoa faz bem ou em profusão e as outras não. Assim, um homem que conquista muitas mulheres faz disputa. Do mesmo modo, um bom caçador traz para casa muita comida, e outros homens que estão panema, não. Se alguém abre uma roça grande, os demais desejarão fazer o mesmo. Alguém que fala bem o português faz inveja para quem não conhece tão bem essa língua.

No caso dos bens cuja aquisição necessita de dinheiro, a tentativa 
das famílias é de acessar as posições assalariadas e os cursos e formações que poderão levar seus filhos a acessá-las. Esse é também um dos motivos para enviar os jovens à cidade no intento de terminar o ensino médio e, depois, cursar a universidade (licenciatura intercultural) ou cursos técnicos (em enfermagem): a expectativa é que futuramente esses jovens possam ser contratados nas aldeias como técnicos de enfermagem e professores.

Alguns jovens que vivem em Macapá já concluíram o ensino médio, enquanto aqueles que estudam nas aldeias, ainda não. Um professor, cujo filho foi um dos primeiros a estudar na capital, disse-me que depois dele outras famílias o imitaram e enviaram seus filhos à cidade. Segundo ele, esse movimento ocorreu para não ter desigualdade. Foi esse mesmo termo, em português, que um pesquisador wajãpi usou para me explicar o porquê de as pessoas procurarem fazer o que os outros fazem, ou comprar o que os outros compram: "se tem um rapaz que sabe bem fazer artesanato e outro não sabe, isso é jirõarõa". O termo se aplica também ao caso dos assalariados que compram roupas caras, motosserras, motores etc. Como outro homem me disse, "porque um fez aquilo e outro quer fazer também igual dele".

Dizem que pessoas fazem preconceito ao comprarem muito para si e não dividirem com os demais, ou por se gabar de algo que os outros não podem ter ou não sabem fazer. Segundo uma interlocutora, "como [nome de um homem wajãpi] falou 'sou milionário, comprei terreno, tenho máquina de lavar'. Ele falou isso, isso é jirõarõa”. Outra pessoa me explicou: "É, como por exemplo: tem algumas pessoas, algumas mulheres que aprendeu bem falar português e outros não sabem. Aí alguém sabe bem falar português vai falar pra ele: 'Por que você não aprende língua portuguesa? Eu aprendi mais que você'”.

No caso específico dos bens - eu não saberia comentar os exemplos que dizem respeito a habilidades linguísticas, agrícolas ou cinegéticas -, o ideal é que não se faça preconceito ou disputa, pois há pessoas que não têm condições de comprar as mesmas coisas, e elas poderão ficar com ciúme. Aqueles que têm muitas coisas oriundas da cidade, em geral, queixam-se de roubos a suas casas quando saem para ir à roça ou para visitar alguma aldeia mais distante. Numa entrevista 
com uma moradora da região de Mariry, ela me disse o seguinte sobre esse assunto: "Jirõarõa é outro que tem, outro que não tem. Como por exemplo, outro pinta com maquiagem, outro não pinta, pinta só urucu. Aí esse jirõarõa", e prosseguiu: "por isso essa mulher procura de roubar. Aí depois ela viu e rouba. Assim acontece aqui, acontece muito. [...] outra pessoa rouba panela, prato, colher".

É por esse motivo que os Wajãpi trancam suas malas com cadeados ou guardam coisas caras (combustível, por exemplo) em quartos fechados, nas aldeias em que eles existem. Cesar Gordon (2006, p. 174) especula que foi para esconder os bens das famílias que os Xikrin passaram a construir cozinhas fechadas. Entre os Wajãpi, Catherine Gallois (2004) já apontara a existência de "casas de guardar coisas", construções fechadas com a finalidade de armazenar pertences. Antes mesmo do afluxo de mercadorias, os Wajãpi adotavam estratégias de não visibilizar, por exemplo, tudo o que um homem caçou ou pescou (CAMPBELL, 1995, p. 148).

Penso ser possível pensar os roubos como dádiva involuntária, tal qual trata Laura Bathurst (2009) em seu trabalho sobre os Tacana na Bolívia. Além disso, se alguém tem muitos bens, pode acontecer de os outros pedirem presentes. Negar tais solicitações pode fazer com que a pessoa seja considerada sovina, disposição contrária ao ideal de generosidade dos Wajãpi.

Fazer preconceito, disputa, desse modo, é considerado mal visto. Os outros irão querer fazer o que aquela pessoa faz. No caso dos bens cuja compra envolve dinheiro, isso nem sempre é possível, gerando ciúme e, potencialmente, roubos ou pedidos, forçando a generosidade e a distribuição das coisas ${ }^{17}$. Dominique T. Gallois se refere a explicações de um interlocutor sobre o ciúme entre os Wajãpi:

\footnotetext{
17 Peterson (1993), escrevendo sobre populações aborígenes na Austrália, cunha o termo "demand sharing", compartilhamento demandado, para se referir a um modo de pôr em curso a generosidade a partir de pedidos explícitos (verbalizados ou não) que uma pessoa faz a outra que tem mais; esse tipo de distribuição não faz a pessoa que pede se endividar (PETERSON, 2013, p. 167). No caso dos Yolngu com quem fez pesquisa de campo, pedidos eram comuns, seja com relação à comida ou ao dinheiro advindo de benefícios sociais, desigualmente distribuídos entre os membros das comunidades. No contexto amazônico, Ewart (2013a, p. 37) utiliza-se da ideia de demand sharing para pensar os pedidos por coisas que os Panará fazem entre si, e Colleoni (2016) usa do mesmo conceito ao refletir acerca dos pedidos dos Waorani (Amazônia peruana) aos donos de caxiri e aos não índios com quem convivem.
} 
Como explicava brilhantemente o chefe Kumai, quando ele refletia, anos atrás, sobre os primeiros distúrbios criados pelo acesso desigual às 'coisas dos brancos', um dos únicos mecanismos que leva os Waiãpi a redistribuir entre si é o ciúme. O que um tem - uma roça, uma casa, um caminho de caça, etc... - todos devem ter. Com o dinheiro, ocorre o mesmo (GALLOIS, 2000, p. 7, grifos meus).

Em uma entrevista, a mesma antropóloga (GALLOIS et al, 2001, p. 107) ainda afirma que, entre os Wajãpi, "quando você quer uma coisa, você demonstra o ciúme, até a pessoa te dar aquilo que [você] quer".

Ser o iniciador de uma moda pode ser uma ação neutra. Se essa ação está relacionada à sovinice e ao acúmulo de bens, porém, seu iniciador pode passar a ser malquisto. Fazer disputa, ou preconceito, pelo que entendi, é sempre algo negativamente valorado: ocorre quando alguém inicia uma moda que os demais não poderão seguir - seja por não ter dinheiro para comprar determinados bens, seja por não saber fazer algo.

\section{Considerações finais}

Dediquei-me aqui a apresentar alguns modos pelos quais os Wajãpi refletem sobre a aquisição e uso de certos objetos, mercadorias, bens, modas. Em primeiro lugar, apresentei a ideia de imitação a partir de diálogos com bibliografia sobre corpo. Em seguida, prossegui à apresentação do modo pelo qual a aquisição de certos bens e a execução de certas atividades inscreve-se numa lógica de tipo iniciador-seguidores. Com relação a isso, tratei da dupla dinâmica de imitação e fazer preconceito. A partir dela apresentaram-se também algumas disposições que são positiva e negativamente valoradas: a sovinice malquista e sua contraparte, a generosidade estimada.

Tendo, neste artigo, traçado um esboço inicial dessas dinâmicas, muitas pontas ficam soltas: seria possível partir daí para a compreensão da constituição de posições de chefia e prestígio? Quando os Wajãpi dizem que imitam os demais para não haver desigualdade, ou quando se queixam da má distribuição do dinheiro e dos bens, o que entendem 
por igualdade? Esses são apenas alguns exemplos de caminhos que não consegui seguir, mas que sem dúvida podem enriquecer a discussão proposta.

\section{Referências bibliográficas}

BATHURST, Laura. Theft as "Involuntary Gifting" among the Tacana of Northern Bolivia. Tipití: Journal of the Society for the Anthropology of Lowland South America, v. $7, \quad$ n. $2, \quad$ p. 181-204, 2009. Disponível em: http://digitalcommons.trinity.edu/tipiti/vol7/iss2/3. Acesso em: 13 fev. 2017.

CABALZAR, Flora D. Trocas matrimoniais e relações de qualidade entre os Waiãpi do Amapá. 1997. 297 f. Dissertação (Mestrado em Antropologia Social), PPGAS, USP, São Paulo, SP, [1997].

CAMPBELL, A. T. Getting to know Wai Wai: An Amazonian ethnography. London, New York: Routledge, 1995.

COLLEONI, Paola. Becoming Tamed. The Meaning of "Becoming Civilized" among the Waorani of Amazonian Ecuador. Tipiti: Journal of the Society for the Anthropology of Lowland South America. v. 14, n. 1, p. 72-101, 2016. Disponível em: http://digitalcommons.trinity.edu/tipiti/vol14/iss 1/5. Acesso: 26 jan. 2017.

DAL POZ, João. Dádivas e dívidas na Amazônia: parentesco, economia e ritual nos Cinta-Larga. 2004. 346 f. Tese (Doutorado em Ciências Sociais) - IFCH, UNICAMP, Campinas, SP, [2004].

EWART, Elizabeth. Black paint, red paint and a wristwatch: The aesthetics of modernity among the Panará in Central Brazil. In: EWART, Elizabeth; O'HANLON, Michael (Org.). Body arts and modernity. Wantage: Sean Kingston Publishing, 2007. p. 36-52.

Demanding, Giving, Sharing, and Keeping: Panará Ideas of Economy. The Journal of Latin American and Caribbean Anthropology, v. 18, n. 1, p. 31-50, 2013a. Disponível em: http://onlinelibrary.wiley.com/doi/10.1111/jlca.12002/full. Acesso: 13 fev. 2017.

Space and society in central Brazil: a Panará ethnography. London, New York: Bloomsbury Academic, 2013b.

GALLOIS, Catherine J. S. Sentidos e formas do habitar indígena: entre mobilidade e sedentarização. Estudo de caso entre os Wajãpi do Amapá. 2004. 167 f. Dissertação (Mestrado em Planejamento Urbano e Regional) - IPPUR, UFRJ, Rio de Janeiro, RJ, [2004]. 
GALLOIS, Dominique T. Migração, guerra e comércio: os Waiãpi na Guiana. São Paulo: FFLCH-USP, 1986.

O Movimento na Cosmologia Waiãpi: criação, expansão e transformação do universo. 1988. 417 f. Tese (Doutorado em Antropologia Social) - PPGAS, USP, São Paulo, SP, [1988].

Arte iconográfica Waiãpi. In: VIDAL, Lux (Org.). Grafismo indígena: estudos de antropologia estética. São Paulo: Studio Nobel/Edusp/Fapesp, 1992. p. 209230.

Situação atual dos Waiãpi no Amapá e viabilidade de execução de Projeto "Recuperação do ambiental e despoluição de áreas degradadas por garimpo na TI Waiãpi”. Relatório PD/A. 2000. (Documento não publicado).

Kusiwa: pintura corporal e arte gráfica Wajãpi. Rio de Janeiro: Museu do Índio/FUNAI, 2002.

. Os Wajãpi frente à sua "cultura". Revista do Patrimônio Histórico e Artístico Nacional, Rio de Janeiro, v. 32, p. 110-129, 2005.

Terra Indígena Wajãpi: da demarcação às experiências de gestão territorial. São Paulo: Iepé, 2011.

. Donos, detentores e usuários da arte gráfica kusiwa. Revista de Antropologia, São Paulo, v. 55, n. 1, p. 19-49, 2012. Disponível em: http://www.revistas.usp.br/ra/article/view/46956. Acesso em: 13 fev. 2017.

GALLOIS et al. Essa incansável tradução: entrevista com Dominique Tilkin Gallois. Sexta Feira, São Paulo, v. 34, 2001.

GORDON, Cesar. Economia selvagem: Ritual e mercadoria entre os índios XikrinMebêngôkre. São Paulo: Ed. UNESP/ISA; Rio de Janeiro: NUTI, 2006.

GREGORY, Chris. A. Gifts and commodities. London/New York: Academic Press: 1982.

Savage money: the anthropology and politics of commodity exchange. Amsterdam: Harwood Academic, 1997.

GROTTI, Vanessa. The Wealth of the Body: Trade Relations, Objects, and Personhood in Northeastern Amazonia. The Journal of Latin American and Caribbean Anthropology, v. 18, n. 1, p. 14-30, 2013. Disponível em: http://onlinelibrary.wiley.com/doi/10.1111/jlca.12001/full. Acesso em: 13 fev. 2017.

HUGH-JONES, Stephen. Yesterday's luxuries, tomorrow's necessities: business and barter in northwest Amazonia. In: HUMPHREY, Caroline; HUGH-JONES, Stephen (Org). Barter, exchange and value: an anthropological approach. Cambridge: 
Cambridge University Press, 1992. p. 42-74.

KELLY LUCIANI, José Antonio. Sobre a antimestiçagem. Curitiba: Species - Núcleo de Antropologia Especulativa; Desterro, [Florianópolis]: Cultura e Barbárie, 2016.

LAGROU, Els. Rir do poder e o poder do riso nas narrativas e performances Kaxinawa. Revista de Antropologia, São Paulo, v. 49, n. 1, p. 55-90, jun. 2006. Disponível em: http://dx.doi.org/10.1590/s0034-77012006000100003 Acesso: 26 jan. 2017.

NUNES, Eduardo S. De corpos duplos: mestiçagem, mistura e relação entre os Karajá de Buridina (Aruanã-GO). Cadernos de Campo, São Paulo, v. 1, n. 19, p. 113-134, 2010.

OLIVEIRA, Joana Cabral de. Entre Plantas e Palavras: Modos de Construção de Saberes entre os Wajãpi (AP). 2012. 282 f. Tese (Doutorado em Antropologia Social) PPGAS, USP, São Paulo, SP, [2012].

PAULA, Camila Galan de. Num mundo de muitos corpos: um estudo sobre objetos e vestimentas entre os Wajãpi no Amapá. 2015. 231 f. Dissertação (Mestrado em Antropologia Social) - PPGAS, USP, São Paulo, SP, [2015].

Roupas que combinam e uma discussão sobre calças. Ponto Urbe, São Paulo, n. 19, p. 1-16, 2016. Disponível em: http://dx.doi.org/10.4000/pontourbe.3187. Acesso em: 10 jan. 2017.

PELLEGRINO, Sílvia P. Imagens e Substâncias como Vínculos de Pertecimento: as experiência Wajãpi e Yanomami. 2008. 223 f. Tese (Doutorado em Antropologia Social), PPGAS, USP, São Paulo, SP, [2008].

PESQUISADORES WAJÃPI. I'ã: Para nós não existe só "imagem". 2008. Disponível em: <http://www.apina.org.br/documentos/Ia-Para_nos_nao_existe_so_imagem.pdf >. Acesso em: 10 abr. 2015.

PESQUISADORES E PROFESSORES WAJÃPI. Kusiwarã. [S. 1]. 2009.

PETERSON, Nicolas. Demand Sharing: Reciprocity and the Pressure for Generosity among Foragers. American Anthropologist. v. 95, n. 4, p. 860-874, 1993.

On the persistence of sharing: personhood, asymmetrical reciprocity, and demand sharing in the Indigenous Australian domestic moral economy. The Australian Journal of Anthropology, v. 24, p. 166-176. 2013.

ROSALEN, Juliana. Aproximações à temática das DST junto aos Wajãpi do Amapari: um estudo sobre malefícios, fluidos corporais e sexualidade. 2005. $195 \mathrm{f}$. Dissertação (Mestrado em Antropologia Social) - PPGAS, USP, São Paulo, SP, [2005].

SEEGER, Anthony; DA MATTA, Roberto; VIVEIROS DE CASTRO, Eduardo B. A construção da pessoa nas sociedades indígenas brasileiras. Boletim do Museu 
Nacional, Série Antropologia, Rio de Janeiro, n. 32, p. 2-19, 1979.

TINOCO, Sílvia. L .S. M. Joviña, cacique, professor e presidente: as relações entre o conselho Apina e os cursos de formação de professores Waiãpi. 2000. $148 \mathrm{f}$. Dissertação (Mestrado em Antropologia Social), PPGAS, USP, São Paulo, SP, [2000].

VAN VELTHEM, Lúcia H. O belo é a fera: a estética da produção e da predação entre os Wayana. Lisboa: Museu Nacional de Etnologia: Assírio \& Alvim, 2003.

VILAÇA, Aparecida. O que significa tornar-se outro? Xamanismo e contato interétnico na Amazônia. Revista Brasileira de Ciências Sociais, São Paulo, v. 15, n. 44, p. 56-72, out. 2000. Disponível em: <http://dx.doi.org/10.1590/S0102-69092000000300003>. Acesso em: 02 dez. 2010.

VIVEIROS DE CASTRO, Eduardo. Araweté: os deuses canibais. Rio de Janeiro: J. Zahar Editor/ANPOCS, 1986.

. A inconstância da alma selvagem: e outros ensaios de antropologia. São Paulo: Cosac Naify, 2006.

WALKER, Harry. Demonic trade: debt, materiality and agency in Amazonia. The Journal of The Royal Anthropological Institute, v. 18, n. 1, p. 140-159, 2012. Disponível em: http://onlinelibrary.wiley.com/wol1/doi/10.1111/j.14679655.2011.01735.x/full. Acesso: 13 fev. 2017.

Wild Things: Manufacturing Desire in the Urarina Moral Economy. The Journal of Latin American and Caribbean Anthropology, v. 18, n. 1, p. 51-66, 2013. Disponível em: http://onlinelibrary.wiley.com/doi/10.1111/j.19354940.2012.01254.x/full. Acesso em 13 fev. 2017. 